\title{
A CONTAÇÃO DE HISTÓRIA NA EDUCAÇÃO INFANTIL
}

\author{
Eliane Maria de Lima Paixão ${ }^{1}$ \\ Enedina Rodrigues de Jesus Pereira ${ }^{2}$ \\ Rosângela Silva Santos ${ }^{3}$ \\ Suely Francisca Soares Jacobes ${ }^{4}$
}

RESUMO: O presente artigo tem como tema a contação de história na educação infantil, como linha de pesquisa é voltado à docência na educação infantil. Enfatiza-se a contação de história no desenvolvimento e na aprendizagem na educação infantil, tendo como objetivo resgatar a importância, bem como aprofundar as discussões acerca deste tema como estímulo na aprendizagem da leitura na educação infantil, sinalizando para o imperativo da recuperação de contar histórias infantis. Da problematização sobre o tema sobre, os professores de educação infantil têm incentivado e valorizado a prática de contar histórias em suas aulas, pois o aluno ao ler e ouvir as histórias possibilita a aprendizagem significativa, portanto a contação de história pode interferir positivamente na socialização, imaginação, motivação, criatividade, desenvolvimento, fantasia, atenção das crianças pequenas, permitindo a compreensão das palavras, pela história, pela leitura, pelo ouvir, promover a aprendizagem. Por fim espera-se com esse artigo que os educadores entendam que a diversidade das histórias infantis ao serem contadas levam os alunos para além da imaginação, tem um caráter educativo.

\section{INTRODUÇÃO}

O presente artigo tem como tema: a contação de história na educação infantil, sendo que sua elaboração justifica-se, pois este tema é relevante, na medida em que se propõe a compreender que a contação de história faz parte da infância, sendo competência do professor o desenvolvimento de estratégias para a sua utilização, onde os seus alunos aprendam com prazer e satisfação, a contação de história infantil gera alegria.

\footnotetext{
I Graduada em Pedagogia pela Faculdadeds Integradas Mato-Grossense de Ciências Sociais e Humanas, Especialista em Educação Infantil e Alfabetização pelo Instituto Cuiabano de Educação - ICE.

${ }^{2}$ Graduada em Pedagogia pela Universidade Federal de Mato Grosso - UFMT, Especialista em Educação Infantil e Alfabetização.

3 Graduada em Pedagogia pela Universidade Norte do Paraná - UNOPAR, Especialista em Educação Infantil e Alfabetização pela Faculdade Afirmativo.

4 Graduada em pedagogia pela UNIP - Universidade Paulista, Graduada em História pela UFMT Universidade Federal de Mato Grosso, Especialista em Gestão Municipal pela UNEMAT - Universidade do Estado de Mato Grosso, Especialista em Educação Especial pelo UNINTER - Centro Universitário Internacional, Especialista em Educação Infantil pela Faculdade UniBF.
} 
A problematização sobre o tema, os professores de educação infantil têm incentivado e valorizado a prática de contar histórias em suas aulas, pois o aluno ao ler e ouvir as histórias possibilita a aprendizagem significativa.

Os objetivos que pretendem através deste artigo: resgatar a importância de contar e ouvir histórias na educação infantil, incentivar a prática de contar e ouvir história para as crianças, resgatar o contar e ouvir histórias infantis; como momentos agradáveis, de prazer; desenvolver a fantasia, a imaginação, a concentração e a criatividade; promover o hábito de contar e ouvir histórias.

Os autores utilizados para a elaboração deste artigo foram: Aguiar, (2001), Coelho (1995), Costa, (2007), entre outros.

\section{DESENVOLVIMENTO}

A terminologia literatura passa a ser utilizada após o século XVIII e o seu sentido permanece o mesmo até hoje. De acordo com Costa (2007, p. 33): “[...] a literatura se constitui num gênero textual específico, com beleza da linguagem, conhecê-la e entendê-la significa participar da literatura, sendo que na escola pode exercer diferentes funções, tais como informar, educar, entreter, persuadir ou expressar uma opinião ou ideia”.

De acordo com Marques (2009, p. I6), a palavra "literatura" deriva latin: littera, que significa letra, isto é, um sinal gráfico que representando, através da escrita, os sons da linguagem. Dessa forma, a literatura faz ligação com a língua escrita. Logo, desde sua origem, o termo favorece um conceito que avalia a importância da escrita que a oralidade. Não é possível que se perca a origem da literatura, quanto à narrativa, está nos relatos orais, enquanto a lírica está ligada à música.

No Brasil, apenas no século XX, aparece o maior escritor para crianças, Monteiro Lobato que rompe com os pensamentos estereotipados, reis, rainhas, animais e príncipes de origem européia e cria uma narrativa de identificação infantil, não apenas com as personagens, como também com as situações familiares e afetivas.

Nesse mundo do faz-de-conta de Lobato, o maravilhoso passa normalmente a integrar o real, isto é, o inventado passa a ter valor de realidade ficcional.

Então, desde o século XX até hoje a sociedade é representada através da literatura em seus aspectos históricos e sociais. E diversas reações aconteceram, mas somente acontece um 
aumento dos leitores com a função da instituição escolar no incentivo da leitura na Lei no 5692/7I que reformou (e depois foi reeditada) o ensino fundamental e médio e dando valor ao uso da literatura infantil.

Dessa forma havia traços culturais ainda pouco explorados, a escola começa a dar voz a essa necessidade que surgia. Entretanto o que houve foi que o cotidiano das massas, do povo não teve acesso aos livros, para os pobres, os problemas se resolvem sem ler ou escrever. Depois da ditadura militar nos anos 70 é que procurou então fazer um caminho da oralidade à leitura que foi um processo perdido na construção da nação brasileira (AGUIAR, 200I).

Um aspecto de grande importância a ser destacado é a qualidade literária através da leitura. O Brasil já possui bons autores para elas porque já cresceu muito e evoluiu na ultimamente. Entende-se que os assuntos deveriam e foram desmistificados.

No Século XX a sala de aula atendia uma classe dominante, o professor era considerado o detentor do saber, o aluno, o único responsável pelo fracasso. E neste caso, o que se pensa hoje e o que se sabe é que a educação vê o educando com papel ativo, sendo um ser em formação e transformação. A partir também de 197I com a LDB (Lei de Diretrizes e Bases da Educação), a Literatura Infantil é abordada na educação.

O processo de ler é uma atividade em que é preciso a compreensão anterior à própria leitura e até a rapidez envolve estratégias que precisa ser utilizado com atenção quando trata com crianças pequenas. É preciso haver a exploração do saber literário e que até a simples contação de histórias.

Como educadoras, precisamos conhecer os tipos diversos gêneros textuais para crianças e também na estrutura organizacional da literatura infanto-juvenil: o mito, a lenda, a fábula, o apólogo, o conto (de fadas ou não), a novela, a crônica e as narrativas mistas dos demais gêneros.

Assim quando se utiliza a literatura infantil, ainda nas séries iniciais haverá uma contribuição para aluno e se estimula a interpretação, além de promover o aspecto importantíssimo da reflexão.

Aguiar (200I) classifica e diz que a idade exerce influência nos interesses pela leitura e apresenta as fases escolares, classificando as idades, porém não se podem esquecer quem escolhe de livros e/ou histórias erradas está, por cercear o leitor em formação: 
Pré-leitura (exemplos): Na Educação Infantil e na preparação para a alfabetização e capacidade do desenvolvimento da linguagem oral. Os interesses são por histórias curtas e rimas, muitas gravuras, pois a descoberta se faz pela linguagem visual e as situações falam do cotidiano, lidas ou contadas por adultos. As cantigas também devem ser exploradas, pois o ritmo da música nos remete aos primeiro poemas que escutamos em nossa infância. Aos 02 anos, por exemplo, procuremos histórias om animais principalmente domésticos e que falem de brinquedos que lhes sejam familiares. A dramatização chama muito a atenção de crianças nesta fase, diz [...]. O que ocorrerá também é que a criança gostará de ouvir diversas vezes a história e está sempre pedindo: conte outra vez.

Quanto à criança recontar a história, deverá ser a sua maneira utilize massa, argila, papel, impressão com objetos, etc.

A literatura adulta também é explicada, mas é importante falar que se ressaltar que as preferências variam e os interesses também. Eles têm a ver com o nível socioeconômico de cada um, por isso é importante para o professor, provocar o interesse e ter a chance de formar leitores competentes.

Para aprender a ler, é preciso saber como se faz aquele que vai ler e também como este lê. No caso, aqui vai se mostrar como uma criança na Educação Infantil vai se formar através de histórias que os professores contam.

Aguiar (200I) diz que a leitura, embora seja uma ação corriqueira nas áreas urbanas, ela não é natural e também não é de mesmo modo em cada pessoa ou criança. Não lemos como comemos respiramos ou outras coisas do ser humano.

Tem níveis diferentes e fatores diferentes como: os interesses, os hábitos, as intenções e as técnicas de leitura. Nota-se que a história da literatura se aproxima da história do livro também, pois eles remontam a vinte mil anos antes da nossa era.

Neste artigo não podemos deixar de falar da importância da família e dos professores neste processo, porque ela é um modelo a serem imitados e mesmo com problemas de falta de leitura para os pais, eles depositam em seus filhos a esperança de eles serem diferentes deles. E isso é com a escrita. Só que o importante essencial é o comprometimento, leitura conjunta e diálogo sobre o que foi lido.

Ângela da Rocha Rolla (1995) estudou professores, começando pelo não leitor, aquele com história de distância dos livros, principalmente quando são crianças. É uma pessoa em 
que outros hábitos culturais também são distantes, como o cinema, teatro, música, esporte e outros.

Já o leitor apressado é um indivíduo dinâmico e ocupado, só lê para se informar dos acontecimentos recentes.

O leitor superficial escolhe os textos ao acaso e geralmente informativos de massa ou gêneros já consagrados como o romance romântico.

Então há o leitor compulsivo que vai desde a história em quadrinhos ao último lançamento do mais comentado livro da época. Lê tudo a toda hora. Diferente é o leitor técnico que faz leituras para estudos. A leitura está ausente, porque a científica lhe toma todo o tempo. Considera sua leitura como cansativa e a faz por obrigação.

Tem também o leitor escolar que é aquele com o objetivo de indicar obras literárias, lê rápido sem tirar proveito.

O leitor profissional não é ingênuo, pois lê para analisar estilos e busca o valor estético das obras e seu cotidiano é a leitura literária e a produção de textos. Frequenta livrarias e círculo de leitores e esta atividade é realizada com prazer. E por último a autora Rolla (I995, p. III) fala do professor leitor diletante, um leitor que lê sem conhecimento prévio, por puro prazer. Prefere literatura de consumo. Os critérios para ler são ao acaso, sabor do momento e não possui bagagem teórica para avaliar o que leu.

É importante, levarmos as crianças em ambientes em que as leituras sejam significativas (feiras, bibliotecas públicas, livrarias) e para que habilidades de leitura e escrita floresçam e se mantenham o foco pode ser direcionado e/ou iniciado em sala de aula.

Outro trabalho estudado fornece sugestões que podem ser aproveitadas pelos professores como o início de uma Cultura Infantil, porque é dentro dela que se realiza a literatura infantil. Mas ainda assim é necessário ampliar o foco e perceber esta Cultura Infantil ainda dentro de uma cultura maior, a partir do que é a infância englobando as Artes, a Mídia, o consumo, as pedagogias (KAERCHER, 2010).

Outros modos são etiquetas em cabides, pastas, caixas (com descrição do que há no interior), assim gavetas, potes e tudo que favorece o uso da escrita, devem ser aproximados da criança tanto na escola quanto em casa. Os jogos são outra estratégia também citada, assim se as crianças colecionam e classificam o material, ex: garrafas com água, descritas 
como água, mas em potes diferentes, assim em suportes também diferentes, redondos retangulares, triangulares; de outras cores: vermelhos, verdes etc.

Coelho (1995, p. 3I) diz que: “[...] A função pedagógica dos Contos de Fadas, quase como regra, era afastar os pequenos dos perigos [...]”, além disso, encontra-se em muitos desses contos, a defesa de valores como a virtude, o trabalho e a "esperteza".

Historicamente, pesquisas virtuais mais recentes dizem que: alguns contos, segundo a investigação, são mais velhos do que os registros literários mais antigos.

Muitas estratégias podem ser efetuadas e o professor deve registrar os projetos desenvolvidos em sala, nos passeios, nas atividades significativas, mostrando o quanto é importante para os pequenos este trabalho para o futuro "adentramento" delas no universo da escrita.

Então, o trabalho deste profissional, se já não acontece em casa, vai acabar sendo feito na escola e os professores ampliam seus repertórios ou cria-los, dependendo da própria cultura do indivíduo ainda pequeno. Não é para apresentá-los à "boa” leitura.

Costa (2007, p. III-II2) diz que assimilar o aprendizado com os textos de histórias é "produzir energia capaz de dar vida ao cérebro, às inteligências, à sensibilidade. Possibilita um embate que o leitor crítico, trava com os textos que lê".

Chartier (200I) afirma que: a revolução do texto eletrônico é ao mesmo tempo uma revolução da técnica de produção e reprodução dos textos, uma revolução do suporte da escrita e uma revolução das práticas de leitura.

Esse papel é importante e precisa ser atualizado. O profissional precisa buscar informações o tempo todo, observar a realidade dos alunos e a interação deles com os assuntos e/ou histórias que lhe são demonstradas ou contadas. Costa (2007) diz que o livro é responsável na formação da consciência de crianças e jovens, mas como já foi citado, é importante compartilhar com a família, professores e escola. Acrescenta-se que atitude tem brechas, mas ganha preenchimento cada dia com esta nossa sociedade cibernética. É considerado uma propriedade do educador: entender o imaginário da criança, isto porque ela vai, principalmente na faixa aproximada que estamos tentando dissertar, perceber que não é fácil fazer o uso deste recurso, porque a imaginação se encontra como que no ponto crucial onde a percepção, a memória, a geração de ideias, a emoção, a metáfora e, sem dúvida outros aspectos de nossa vida se cruzam e interagem. 
E então na faixa etária de aproximadamente os anos em geral, se descobre que acontece uma abertura das portas de um vasto mundo: as crianças passam a intensificar seus eventos de letramento, portanto se interessar pela escrita.

Uma característica importante para a atividade é que CONTAÇÃO NÃO É LEITURA EM VOZ ALTA e o mais importante é que o clima proposto pelo educador contagie a todos, inclusive ele próprio.

Através de sugestões, de Lúcia Fidalgo ${ }^{5}$ é possível perceber que este trabalho é precedido de preparativos tanto para contar como para ouvir histórias, a seguir o que diz a autora:

I. Escolha uma história que você gosta muito de contar;

2. Leia essa história muitas, muitas vezes;

3. Feche os olhos e imagine o cenário, os personagens o tempo;

4. Pense na voz escolhida para o narrador e os personagens;

5. Execute o seu poder de concentração;

6. Escolha a sua melhor forma de memorização;

7. Conte para alguém antes de contar para todo mundo;

8. Cuidado com sua postura e os vícios de linguagem;

9. Olhe para todos os que te ouvem, o olhar diz muita coisa

Io. $\mathrm{Na}$ hora de contar seja natural deixe falar o seu coração, seduza o seu ouvido para que ele deseje ouvir novamente.

Kaercher (2010) diz que vale lembrar que sempre que vamos contar uma história podemos e devemos lançar mão de técnicas e/ou recursos que nos ajudem a tornar o momento de ouvir a história algo mágico para as crianças. Aponta também algumas pistas importantes:

- Teatro de Fantoches: a história é narrada através dos fantoches que podem ser personagens das histórias ou não. É importante apresentar fantoches feitos por pessoas que conheçam a técnica para que os mesmos apresentem bom acabamento e qualidade no manuseio.

- Histórias sugeridas: a professora, com o auxílio do flanelógrafo ou do avental (vale aqui também usar um blusão de lã onde as gravuras, com lixa ou velcro atrás,

${ }^{5}$ Fonte: Dicas de Lúcia Fidalgo (site acesso em 04/09/2021). 
possam ser "grudadas"), inicia a narrativa com uma imagem e as crianças dão continuidade à história encadeando as demais figuras disponíveis.

- Histórias contadas e desenhadas/modeladas: a professora vai contando a história, fazendo pausas estratégicas em cenas importantes da narrativa, para que as crianças possam desenhar, individualmente ou em grupos, as sequências. É imprescindível que haja espaço e material suficientes para que as crianças possam desenvolver a atividade sem necessitar de deslocamentos (para pedir lápis, papel etc. emprestados).

- Histórias com discos ou instrumentos: o professor vai contando e, com a turma, vai produzindo sons ritmados ou músicas para acompanhar a narrativa. É semelhante a uma peça radiofônica, onde os sons das ações e dos personagens são produzidos, reproduzidos ou inventados pelo grupo. Aqui, vale a criatividade para imprimir marcas singulares em cada personagem, tais como cacoetes, vícios de linguagem, entonação etc.

- Histórias com o uso exclusivo de gravuras: não há narrativa alguma desenvolvida pela professora; as imagens são expostas às crianças (com fotos ou no computador) que irão sozinhas encadeá-las para formar uma narrativa.

Após a exposição, a professora pode pedir que as crianças recontem a história ou não.

- Histórias rimadas: a professora inicia a narrativa e cada criança vai acrescentando um verso, rimado, ao anterior. É semelhante ao repente nordestino ou à trova gaúcha.

O aspecto mais importante é a ludicidade agindo, a partilha, a escuta atenta de todos e os interesses e curiosidades das crianças. É possível promover uma formação de leitores qualificada, comprometida e, sem dúvida, inesquecível.

Todo esse conhecimento aqui demonstrado deve fazer o professor conduzir a criança aos objetivos a seguir: a) aprofundar o gosto pessoal e estimular o gosto da criança pela leitura; b) ter contato com os diversos gêneros literários, tanto da literatura nacional como universal; c) apropriar-se dos modelos dos diversos tipos de leitura, incluindo a recreativa que é aquela mais presente, no universo da faixa etária aqui estudada. Assim, mais tarde uma leitura orientada e depois, a leitura para informação e estudo; d) desenvolver a 
competência da criança para a leitura; promover a interação entre o adulto e a criança, a partir da diversidade de gêneros literários. Enfim nesta fase se cria uma relação afetiva com a Literatura Infantil.

Então para o professor também é necessário que se movimente ao contar histórias e recite poesias com diferentes entonações na voz.

O termo letramento é recente, começou a ser utilizado por professores da Educação e da Linguística (anos 8o) e trata-se de tempo em situações também diversas, mas, em relação à Educação Infantil "ocorre com a alfabetização" e também é muito utilizado mais recentemente nas Ciências Sociais e também com pessoas adultas que anteriormente não sabiam escrever. Assim também o mesmo é utilizado em diferentes espaços, portanto sua definição, ou seja, nem sempre o significado é o mesmo (MORTALLI, 2004).

Esta é uma atividade muito importante em termos de ouvir e ler, junto com o prazer logicamente. Em sendo assim, para a criança, uma boa história tem o poder de divertila e, ao mesmo tempo, estimular sua aprendizagem. Nesta ação, nossa participação é fundamental e procuremos então conduzir e traçar metas aos objetivos que estaremos em contar histórias e estimulá-las a aprender mais. É preciso investir em ações que façamos com que elas ganhem gosto pela leitura e que tenham gosto também pela literatura tanto nacional e universal. Também as leituras recreativas, depois a orientada e depois ainda a de informação e estudo.

Todos sabem que é na Educação Básica que se desenvolve os hábitos de ouvir, falar, ler e escrever, então com autonomia e gosto elas adquirem os conhecimentos.

\section{CONCLUSÃO}

Através dos autores estudados foi possível ver que o desenvolvimento infantil é um processo que ocorre a partir das interações, socialização, fantasia, criatividade, aprendizagem que os alunos vivenciam, sendo assim, a literatura infantil e em especial a contação de histórias é uma atividade interativa e pedagógica, que mediada na prática pelo professor colabora para o desenvolvimento pleno dos alunos.

As histórias contadas e ouvidas possibilitam o contato das crianças com o uso linguagem escrita e falada, levando-as a conhecerem novas palavras, figuras, valores, a usarem a imaginação, desenvolverem a oralidade, a criatividade e o pensamento crítico, bem 
como melhorarem seus relacionamentos com os demais colegas, cria um espaço para novas aprendizagens nas diversas disciplinas escolares, pelo seu caráter lúdico e motivador.

É imprescindível diante da contação de história na educação infantil, que cada educador insira em sua prática pedagógica essa prática, obtendo os benefícios da mesma e saiba utilizá-la de modo adequado, como ferramenta, de prazer, conhecimento e emoção, aonde principalmente a imaginação, propicia o estímulo à leitura e a escrita das crianças na Educação Infantil.

\section{REFERÊNCIAS}

AGUIAR, V. T. de (Coord). Era uma vez... na escola: formando educadores para formar leitores. Belo Horizonte: Formato Ed., 20or.

COELHO, N. A história da história. In: RIBEIRO, R. O Patinho Feio. São Paulo: Editora Moderna, 1995 .

CHARTIER, Roger. A revolução do texto eletrônico - Cultura escrita, literatura e história. Porto Alegre: Artmed, 20or.

COSTA, Marta Morais da. Metodologia do ensino da literatura infantil. Curitiba: IBPEX, 2007 .

KAERCHER, Gládis E. P. da Silva. Brincando com os livros na escolarização inicial. In: DALLA ZEN, Maria Isabel H.; XAVIER, Maria Luísa M. (Org.). Alfabeletrar: fundamentos e práticas. Porto Alegre: Mediação, 2010.

MARQUES, Fabrício. Jornalismo e literatura: modos de dizer. Conexão - Comunicação e Cultura, UCS, Caxias do Sul, v. 8, n. I6, jul./dez. 2009. Disponível: http://www.ucs.br. Acesso em 04/o9/2021.

MORTALLI, Maria do Rosário Longo. Educação e Letramento. SP: UNESP, 2004. 
ROLLA, A. R. R. Professor: perfil de leitor. Tese (Doutorado em Letras - PUC-RS Instituto de Letras e Artes), Porto Alegre, 1995. 